\title{
A Constelação Familiar Sistêmica como uma Ferramenta Pedagógica e de Mediação entre Família e Escola
}

\section{Systemic Family Constellation as a Pedagogical tool and work of Mediatin between Family and School}

\author{
Elizabete Távora Francelino ${ }^{1}$, Fabiana Lima $\mathrm{Abreu}^{2}$, Gesilane Domingos de Sousa ${ }^{3}$, Jorge Fernandes \\ Barbara $^{4}$, Maria de Lourdes Benevides de Magalhães ${ }^{5}$, Maria José Marques Lima ${ }^{6}$, Maria Flávia Coelho \\ Albuquerque $^{6}$, Maria Aparecida de Medeiros ${ }^{7}$
}

\begin{abstract}
${ }^{1}$ Universidade de Trás- os-Montes e Alto Douro , ${ }^{2}$ Instituto Federal de Educação, Ciência e Tecnologia do Ceará , ${ }^{3}$ Universidade do
\end{abstract} Estado do Ceará , ${ }^{4}$ Instituto Árvore da Vida , ${ }^{5}$ Universidade de Fortaleza , ${ }^{6}$ Universidade Federal do Ceará , ${ }^{7}$ Faculdade Cásper Líbero.

\begin{abstract}
Resumo
O presente artigo relata a experiência terapêutica de Constelação Familiar ou Sistêmica em uma Escola de Ensino Fundamental e Médio, da rede pública, em Fortaleza-CE, Brasil. O projeto de Constelação Familiar nesta escola surgiu da grande demanda de apoio aos estudantes com dificuldades de aprendizagem e comportamento, percebida pela equipe técnica. Os procedimentos metodológicos desta pesquisa foram realizados, utilizando como técnicas a terapia de constelação familiar, análise de entrevistas com os alunos, pais e professores, e observação do comportamento dos estudantes que participaram das constelações familiares, dentro da rotina escolar. Os resultados iniciais propostos atenderam a expectativa da intervenção pedagógica.

Palavras-chave: Constelação Familiar Sistêmica, Terapia, Aprendizagem, familia.
\end{abstract}

\begin{abstract}
This article reports on the therapeutic experience of Family or Systemic Constellation in a School of Primary and Secondary Education, of the public network, in Fortaleza-CE, Brazil. The project of Family Constellation in this school arose from the great demand of support to the students with learning and behavior difficulties, perceived by the technical team. The methodological procedures of this research were carried out, using techniques such as family constellation therapy, analysis of interviews with students, parents and teachers, and observation of the behavior of students who participated in family constellations, within the school routine. The initial results proposed met the expectation of the pedagogical intervention.

Keywords: Systemic Family Constellation, Therapy,

Learning, family
\end{abstract}

O presente artigo relata a experiência terapêutica de Constelação Familiar ou Sistêmica na Escola de Ensino Fundamental e Médio, da rede pública, em Fortaleza-CE, Brasil.

O método terapêutico, fenomenológico, denominado Constelação Familiar foi idealizado pelo psicanalista e pedagogo Bert Hellinger (2009). Está presente em vários países, e vem crescendo muito no Brasil. Trata-se de um

método de diagnóstico, um processo de reorganização e equilíbrio dentro dos sistemas aos quais pertencemos, com a família como base do investimento terapêutico.

Sabe-se que a aprendizagem do adolescente está ligada a fatores emocionais e sociais. Desde o período da infância e adolescência as experiências de sua afetividade na família determinarão durante sua vida o progresso ou insucesso de sua carreira estudantil. De acordo com Ramos (2001), a ausência da família nesse processo faz com que o adolescente busque uma identificação com outros grupos sociais, como uma forma de suprir a carência e que por vezes pode não ser uma experiência saudável, que resultará em conflitos pessoais e desvios de personalidade, comprometendo o processo de aprendizagem escolar. Pesquisas mostram que atrás dos transtornos de aprendizagem e do fracasso escolar, vemos situações complexas de desestrutura familiar que tem como o cerne a família.

No Brasil, a participação familiar no processo de aprendizagem de crianças e jovens, é lei, e está prevista na Constituição Federal Brasileira de 1988, art. 227, que orienta que é dever da família, da sociedade e do Estado assegurar à criança, ao adolescente e ao jovem prot com absoluta prioridade, o direito à vida e cuidados como saúde, alimentação, educação.

O projeto de Constelação Familiar, portanto, surgiu, na referida escola, partindo da grande demanda de apoio, aos estudantes com dificuldades de aprendizagem e comportamento, percebida pela equipe técnica. Além do mais, constatou-se, por meio de relatos escritos pelos próprios alunos, em um projeto escolar, nas aulas de Desenvolvimento Pessoal e Social, que a família era o cerne dos conflitos, que repercutiam na aprendizagem escolar, na motivação, na disciplina, e para muitos era a geradora de traumas psicológicos. A partir dessa realidade, uma professora 
da escola contatou um terapeuta de constelação familiar que se dispôs a construir uma proposta integrando a visão sistêmica da terapia de constelação familiar dentro da rotina da escola, tendo por base o trabalho desenvolvido por Marianne Franke (2009) em escolas da Alemanha.

O projeto pode ser considerado também como formulação de uma Cultura de Paz, já que, a construção de relações humanas, nas condutas e "na expressão do emocionar humano" (Matos; Pierre, 2014:25), são valores para a construção de um mundo em que a paz seja uma realidade. A cultura de paz é algo possível de ser construído em todos os espaços, pois:

Toda relação humana implica determinado modelo de convivência que pressupõe determinados valores, formas de organização, sistemas de relação, normas para enfrentar conflitos, formas linguísticas, modos de expressar os sentimentos, expectativas sociais e educativas, maneiras de exercer o cuidado etc. E isto é assim porque não há possibilidade de viver sem conviver - nós, humanos, somos seres sociais e precisamos dos outros para a própria subsistência (Jares; Xesús, 2006:15).

Justamente porque aprender a conviver é algo inerente a qualquer processo educativo (Jares, 2010, p. 15), seja no âmbito familiar ou nos sistemas educacionais; é na escola que se pode encontrar um dos ambientes ainda mais propícios para que a aprendizagem da convivência ocorra.

É nesse sentido que a experiência realizada na Escola alvo deste artigo, merece destaque, por ter escolhido percorrer, há alguns meses, essa trajetória civilizatória, de busca do entendimento de que o sentido das coisas não está na realidade objetiva, está na história e na meta perseguida. O grupo de professores e o constelador familiar à frente deste trabalho que ora será detalhado, buscaram o sentido de observar a transcendência e imanência do educar, pela construção de laços afetivos.

A relevância da experiência está justamente por se apresentar como real porta de saída, na melhoria das condições de ensino no âmbito da escola, como também impactando todo o sistema educacional e familiar. Isso pode se dizer que seja o objetivo da educação, como descrito pelo educador japonês Tsunessaburo Makiguchi (apud Ikeda; Daisaku, 2017:143), no início do século 20 - "não deve ser definido por eruditos nem para fins específicos de outros grupos. Deve ser o mesmo que o objetivo da vida. Deve capacitar o aluno a alcançar uma vida feliz.".

\section{Abordagem sistêmica}

Os desafios econômicos, sociais e tecnológicos enfrentados pela humanidade, nos dias atuais, exigem cada vez mais o desenvolvimento de uma percepção diferenciada dentro dos sistemas sociais, culturais e relacionais, que possam favorecer o equilíbrio dos seres humanos. Historicamente, a teoria dos sistemas, teve seu início com o biólogo Ludwig Von Bertalanffy, tendo uma maior difusão a partir dos anos 50 . Bertalanffy baseou sua pesquisa numa visão diferente do reducionismo científico, abordando os grupos sociais como organismos, como sistemas abertos em interação com o ambiente (Cansanção; Tenório, 2012).

A partir deste pensamento surgiram diversas escolas sistêmicas, dentre elas, a abordagem sistêmica fenomenológica de Bert Hellinger (2009) que ganha destaque fundamental no que se refere ao conceito de sistema. O sistema pode ser definido como um conjunto de elementos que permanecem unidos ou vinculados em função de um interesse comum ou de forças que o permeiam. Portanto, trata-se de um complexo de elementos em interação, nele as particularidades dos indivíduos não explicam o comportamento de todos. Dessa forma ao analisar um sistema familiar não basta imaginar a soma das análises de seus membros.

Entender a sociedade como um sistema possibilitou maior preocupação com os problemas da sociedade, do que com os problemas biológicos individuais, visto que o sistema é entendido como um complexo de elementos em constante interação, organizados em subsistemas e por fronteiras. A partir desse conceito é possível definir família como um sistema, pois tem um funcionamento como tal, sendo os subsistemas caracterizados pelos indivíduos que vivem em interação, apesar de as particularidades dos indivíduos não explicarem o comportamento de todos.

$\mathrm{O}$ pensar sistêmico não pode ser condicionado à psicoterapia, mas direcionado a uma nova forma de ver, perceber e entender o mundo e a vida. Uma possibilidade de se distanciar das verdades estabelecidas e dos paradigmas definidos, para poder pensar em outras hipóteses e buscar novas alternativas que possibilitem encontrar todos os recursos necessários para a melhor percepção da situação que se apresenta à primeira vista, pois só mudando o olhar sobre as coisas, teremos a capacidade de transformá-las.

A pedagogia sistêmica surgiu a partir do trabalho sistêmico fenomenológico de Bert Hellinger, com base no respeito e no amor à família e tem uma postura voltada aos princípios e leis que geralmente são inconscientes e denominadas como "Ordens do Amor" (2007). O trabalho de Marianne Franke-Gricksh, com formação em terapia familiar e sua experiência como educadora, é expoente na área, ao publicar em 2001 o livro "Você é um de Nós". Franke (2009:21) explica "gradualmente consegui ver nas crianças os representantes de suas famílias com suas leis, suas dinâmicas próprias e suas tarefas particulares". Iniciou o trabalho na escola com seus alunos, denominando-o “jogo familiar", obtendo resultado favorável no sistema escolar e familiar. Surge então um novo olhar dentro do sistema educativo que se encontra inter-relacionado ao sistema familiar e ao sistema social, que fazem parte da escola.

\section{Lealdade aos pais do ponto de vista sistêmico}

A etimologia da palavra lealdade é lei, implicando atitudes de acatamento às leis. No sistema familiar deve prevalecer a justiça e a igualdade, sendo por estas relações que os antepassados legam a vida, e é a vida 
que posteriormente se transmite. Lealdades invisíveis são as interelações transgeracionais e a presença de uma justiça que abrange todo sistema familiar.

Hellinger (2007), fala sobre os princípios das "Ordens do Amor" e aborda a questão do "Dar e Receber" como determinante para o equilíbrio nas relações interpessoais. Seu método das Constelações Familiares aborda as leis nos sistemas humanos - a família, os grupos sociais, as instituições, e trata de reduzir as desordens no sistema familiar. As dimensões sistêmicas que incidem em nossa vida são: a) Dimensão transgeracional: vínculo entre as gerações, antepassados, de nossas raízes e culturas; b) Dimensão intergeracional: vínculo entre pais e filhos, é o lugar que ocupamos e como ocupamos. Os vínculos estabelecidos com os pais serão determinantes no modo como percebemos o mundo e como nos relacionamos com ele. A relação entre os professores e os alunos se situa nesta dimensão; c) Dimensão intrageracional: abrange os laços e a lealdade em relação com a própria geração e o contexto histórico. Relação (entre iguais irmãos, alunos, pai e mãe, professor); d) Dimensão intrapsíquica: aborda o indivíduo como sistema físico, emocional, mental, espiritual.

Nosso mundo familiar, nossas raízes são inscritas em nós, nossa grande alma é transmitida de geração para geração. Os filhos ganham a vida que os pais lhes deram e jamais irão devolvê-la aos pais. Os filhos com a necessidade de compensar abandonam o seu lugar para dar a outros o que eles receberam (aos próprios filhos), essa é uma forma de compensar, reconhecer e agradecer o que receberam. Esta função dos pais gera sentimentos mais primários e profundos em uma pessoa: a segurança e a confiança. Quando os sentimentos são de desconfiança as reações emocionais terão como base o medo, a hostilidade, a defesa, etc.

Portanto, os vínculos familiares são de "sangue" e duram por toda a vida, e são compartilhados com todos da família que antecederam, inconscientemente. Segundo Bert Hellinger (2009), nossa lealdade é tão forte que está a serviço do sistema familiar para reparar as ordens que não foram seguidas em outra geração e que ameaça a continuidade e a força da família. Pessoas que conseguem tomar seus pais como são, e tudo o mais que lhes dão, experimentam essa atitude como um afluxo constante de energia e felicidade, que também os capacita a manter outras relações, onde também dão e recebem abundantemente.

\section{A ordem do amor dentro da Terapia de Constelação Familiar}

Além da relação de pais e filhos (professores e alunos), a alternância entre o dar e o tomar (receber), em todas as demais relações, processa-se entre os envolvidos, como uma das ordens do amor, do seguinte modo: quem recebe algo de alguém retribui-lhe com algo equivalente. O que importa, entretanto, não é apenas a troca, mas o quanto se investe. Um pequeno investimento no dar e tomar traz um pequeno ganho, mas um grande investimento enriquece e é acompanhado por uma sensação de abundância e felicidade. Essa felicidade não nos é dada de graça, ela se constrói Quando investimos muito, temos uma sensação de leveza e liberdade, de justiça e paz.

Outra ordem do amor, segundo Hellinger (2009), é que a consciência de grupo dá a todos o mesmo direito de pertencer. Vela para que esse direito seja reconhecido por todos os que fazem parte do grupo. Preza o vínculo num sentido mais amplo do que a consciência pessoal. Não conhece nenhuma exceção a essa regra: nem mesmo os assassinos de pessoas pertencentes ao próprio grupo. Eles também continuam pertencendo. Se um membro do grupo é excluído ou expulso pelos outros, mesmo que meramente esquecido, porque não se fala mais dele, como frequentemente acontece, por exemplo, com uma criança prematuramente falecida, a consciência de grupo faz com que um outro membro do grupo venha a representar o excluído. Ele imita então o destino daquele, sem ter a consciência disso. Para a consciência do grupo isso é uma compensação, ainda que num nível arcaico. Aliás, a consciência de grupo é uma consciência arcaica. Ela leva a um equilíbrio cego no mal, que não ajuda nem cura ninguém. A injustiça cometida contra os antecessores é apenas repetida pelos sucessores inocentes, mas não é reparada novamente. $\mathrm{O}$ excluído permanece excluído. Para que tal situação de exclusão seja resolvida, é preciso um trabalho de inclusão, de aceitação do membro ou do fato ocorrido, podendo, assim, solucionar uma falha no sistema, com um ato de amor.

Uma outra lei básica se manifesta na atuação da consciência de grupo: em cada grupo há uma hierarquia, de acordo com essa ordem, o que chega primeiro tem precedência sobre os que chegam depois. Por exemplo, um avô tem precedência sobre um neto, um primogênito tem precedência sobre os demais irmãos e um tio tem precedência sobre seu sobrinho. Desse modo, a compensação que obedece à consciência de grupo não faz justiça aos sucessores, pois não os equipara aos antecessores. $\mathrm{O}$ equilíbrio arcaico

contempla os antecessores, desconsiderando os sucessores. Assim, essa consciência de grupo não permite que os sucessores interfiram nos assuntos dos antecessores, seja para fazer valer o direito deles, seja para expiar a culpa em seu lugar, seja ainda para resgatá-los, mesmo que posteriormente, de seu destino funesto (Hellinger, 2009).

Partindo de todas essas premissas, este trabalho pretende apresentar um relato de experiência em constelação familiar sistêmica, como abordagem de terapia familiar e de intervenção pedagógica, em uma escola da rede pública do Estado do Ceará-Brasil.

\section{Metodologia}

Os procedimentos metodológicos deste relato de experiência percorreram os seguintes passos: utilizou-se, como técnicas, a terapia de constelação familiar e, posteriormente ao processo, entrevistas com os alunos e professores, assim como, observação do comportamento dos estudantes que participaram das constelações familiares, dentro da rotina escolar. De 
acordo com Santoro (2012) os relatos de experiência devem contar uma história informativa e como ela se reflete em situações mais gerais que não entra em detalhes irrelevantes sobre o experimento.

A constelação familiar tem como base o método terapêutico fenomenológico, que se manifesta pelos fenômenos, que não são assim tão evidentes, por isso geram incertezas quanto a sua veracidade, e também por não parecer tão óbvio a todos, causa uma dúvida, considerada natural, aos que estejam lá presentes, pois nem tudo que se vê é realmente a realidade dos fatos.

A fenomenologia que caracteriza a Constelação familiar surge para a se repensar a realidade, na sua subjetividade, existencialidade e na transcendência do ser, já se pode olhar a vida como algo inerente a consciência, num grande desafio de se ter algo inovador (Carvalho, 2013).

Vale esclarecer que, no processo terapêutico de constelação familiar, uma pessoa de cada vez é atendida na sessão terapêutica realizada em grupo. $\mathrm{O}$ grupo de estudantes que esteve presente a cada constelação, participou da terapia de constelação de seus colegas, como representantes de pessoas dos sistemas familiares dos alunos que escolheram fazer a mencionada terapia. Ou seja, no grupo terapêutico, participam aqueles que desejam constelar, e os demais que assistem podem auxiliar representando papéis dentro da constelação do colega em terapia. Foram realizadas três sessões de constelação familiar em dias diferentes, durante o mês de abril de 2017, sendo que dois alunos foram constelados em cada uma dessas sessões terapêuticas.

Em um primeiro momento deste projeto escolar a técnica da constelação familiar foi aplicada com os educadores da escola, visando apresentar-lhes de modo teórico e vivencial a abordagem terapêutica em questão. A partir da compreensão e aprovação da direção, equipe técnica, educadores, pais e alunos, o projeto foi iniciado com os estudantes do Ensino Fundamental II e Ensino Médio.

Por questões éticas, os nomes dos alunos, professores e da escola foram omitidos. São utilizadas letras do alfabeto para designar os estudantes citados aqui por meio de seus depoimentos.

\section{Resultados da discussão}

Pensando nos desafios pelos quais a escola vem passando, mundialmente, como falta de atenção, indisciplina e os consequentes conflitos e abandonos escolares que se intensificam, uma escola pública, no Ceará - Brasil, convidou um terapeuta de Constelação Familiar para desenvolver a técnica com alguns alunos na tentativa de ajudá-los com seus problemas e bloqueios familiares, na busca de soluções para questões que envolvem a relação com a família, com os colegas e com os professores. De acordo com Oliveira (2016:103), embora não tenham essa percepção consciente, os alunos percebem quando um professor tenta afastar um pouco seus alunos da origem familiar, para efeitos de aprendizado de convívio social. Ou seja, sempre há ligação entre família e escola.
No começo do ano de 2017, alguns professores fizeram parte da primeira sessão de terapia de constelação sistêmica na referida escola. A receptividade, inicialmente, mostrou-se bem tímida, talvez por ser algo novo e haver uma resistência ao que não é comum. Em outras sessões seguintes já houve um maior interesse e participação. A partir de então, surgiu a ideia de convidar alunos que já haviam procurado alguns professores para falar dos seus problemas familiares e da consequência disso na escola.

No ensino médio do Estado do Ceará, existe um programa chamado Projeto Diretor de Turma (PDT) que teve início no ano de 2006 nas cidades de Eusébio, Madalena e Canindé e que posteriormente se expandiu para toda a rede estadual de ensino público. O objetivo do projeto é a escola ter um professor com mais disponibilidade de tempo para conversar com cada aluno e conhecer a sua realidade. Esse professor, então, passa, por reuniões formais ou informais, todas as informações sobre cada aluno, para que os demais professores e núcleo gestor saibam com que público discente está lidando na escola. Isso pode evitar casos de evasão escolar, melhorar indisciplina e evitar possíveis reprovações (Ceará, 2011).

No ano de 2011 surgiu outro projeto, idealizado pelo Instituto Aliança (IA) e abraçado pela Secretaria de Educação do Ceará (SEDUC), o Núcleo de Trabalho, Pesquisa e Práticas Sociais (NTPPS) que faz parte da reorganização curricular do ensino médio no Estado. Nas oficinas ministradas por um professor de DPS (Desenvolvimento Pessoal e Social) são trabalhados temas que focam o autoconhecimento, pertencimento familiar e social, cuidados com o outro, com o meio ambiente e consigo mesmo (Seduc,2012).

Durante essas aulas e em conversas informais com os professores de PDT e de DPS na Escola, os alunos expunham os seus problemas e angústias, falando do interesse de fazer parte de algum tipo de terapia.

$\mathrm{Na}$ primeira sessão de constelação familiar, poucos alunos apareceram, pelos mesmos motivos prováveis citados antes em relação aos professores. Com o relato de alguns alunos, que participaram e perceberam a importância desta terapia em suas vidas, a procura foi aumentando. São muitas questões, familiares e pessoais de estudantes, que necessitam de atenção e cuidado, mas que estão sendo negligenciadas. Essas questões afloram através dos comportamentos de indisciplina e dificuldades de aprendizagem no ambiente escolar.

Após a realização das sessões de constelação familiar, foram feitas entrevistas, pela equipe pedagógica que acompanhou o processo, com estudantes que participaram e alguns professores que os acompanham em sala de aula que foram realizadas passadas algumas semanas após a intervenção terapêutica.

Nas entrevistas, ao ser questionado como os jovens estavam depois da constelação, foram obtidas respostas como: "Mudou a forma de pensar sobre os meus pais. Passei a entender mais a ausência deles na minha vida. Passei a conversar mais com eles" (depoimento de uma aluna que constelou a relação dela com os pais). 
Outra aluna que constelou a conflituosa convivência com a mãe, declarou:

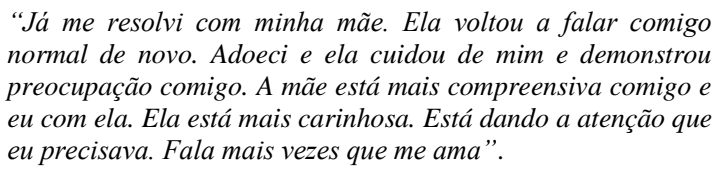

"Já me resolvi com minha mãe. Ela voltou a falar comigo normal de novo. Adoeci e ela cuidou de mim e demonstrou preocupação comigo. A mãe está mais compreensiva comigo e eu com ela. Ela está mais carinhosa. Está dando a atenção que eu precisava. Fala mais vezes que me ama".

$\mathrm{O}$ aluno $\mathrm{G}$ que participou como representante na constelação relatou que se não tivesse participado desta terapia teria matado o padrasto ao descobrir que ele batia na mãe. A constelação familiar, de acordo com seu relato, fez com que ele entendesse que aquilo que o padrasto fazia era padrão da família dele. E também reconheceu o padrão de problemas de conduta da sua própria família. Conversou com a mãe sobre a terapia e ela admitiu a importância de a família toda participar do processo terapêutico.

Segundo Hellinger (2008) bem e mal estão ligados sistemicamente. A visão da constelação familiar está além dos juízos morais, o mal é acima de tudo função de problemas sistêmicos e não é realmente pessoal, ocorre uma trama em larga escala, que acomete as pessoas envolvidas. Conhecendo as pessoas em seus contextos mais amplos, a percepção de liberdade, escolha, responsabilidade, bem e mal mudarão. Entretanto, o que fizermos trará consequências, arcaremos com a culpa e pagaremos o preço pelo mal que provocarmos, ainda que seja por pressão do grupo maior ao qual pertencemos. $\mathrm{O}$ mal se presta a algo que está além da compreensão e controle. Há forças sociais, econômicas e históricas que traçam destinos, que nos influenciam e se impõem à nossa liberdade de opção.

Ao perguntar como estavam depois de algumas sessões da terapia, uma aluna disse que agora estava conseguindo ouvir "não" dos pais. "Já é um grande progresso. Por qualquer coisa eu me zangava e estava lá brigando, por causa da ausência deles. Era como se eu não tivesse paciência com eles".

$\mathrm{Na}$ escola, as mudanças percebidas e relatadas pelos professores foram: maior paciência, mais tranquilidade e melhor dedicação aos estudos. Eles acreditam que isso vem acontecendo porque os jovens não trazerem mais as "dores de casa" para a escola.

Hellinger (2008) explica que existe um desnível irrevogável entre quem dá e quem toma (recebe). É o que acontece, por exemplo, entre pais e filhos ou entre professores e alunos. Pais e professores são basicamente doadores dentro da hierarquia das relações sistêmicas, enquanto filhos e alunos são primariamente tomadores. É verdade que os pais também recebem algo dos filhos, e os professores, por sua vez, recebem também algo de seus alunos. Isso, porém, apenas reduz o desequilíbrio, não o anula. Contudo, os pais já foram filhos, e os professores já foram alunos. Eles conseguem compensar esse desequilíbrio à medida que transmitem à geração seguinte o que receberam da anterior. E seus filhos ou alunos poderão agir da mesma forma. A aluna K que constelou também a relação com seus pais, fala de ter conseguido maior autoconfiança e mudar de atitude diante dos conflitos com colegas e pais, conforme ela relata:

\begin{abstract}
"Minha relação com os colegas melhorou, tirei a casca, passei a confiar mais nas pessoas. Deixei de ficar com raiva, por qualquer coisa eu me zangava. A questão da raiva é que eu trazia muita coisa de casa, muita raiva. Eu passei a ignorar muita coisa que minha mãe falava, e eu me incomodava e rebatia e já saia de casa zangada. Agora ela fala e eu fico calada e aí depois é que eu converso com ela e ela comigo. Agora está tudo bem. Passei a ajudar mais a ela em casa".
\end{abstract}

Outros dois alunos definem assim a constelação familiar: "A constelação na escola é para aqueles alunos que têm problema do passado e não querem falar para ninguém" (Aluno M). "Ela foi criada na escola para resolver problemas familiares ou pessoais" (Aluno E).

Os jovens entrevistados falam sobre a importância da constelação para a resolução de questões escolares e familiares: "tem alguns colegas nossos que não conseguem prestar atenção na aula, são muito inquietos, não conseguem pegar amizade e isso (a terapia de constelação familiar) ajuda a entender" (Aluno U). "Muitas vezes colegas nossos passam por problema dentro de casa mas nós nem sabemos, aí a gente tira brincadeiras às vezes, e a gente não sabe o que a pessoa tá passando naquele momento. Aí ele é convidado para participar da constelação” (Aluno G).

Em relação ao aprendizado, falaram que percebem em si uma maior vontade de fazer algo para participar mais nas atividades da escola, mais dedicação como podemos observar no depoimento a seguir: "Estou melhor. Recuperando notas. Estou começando a ter mais tempo e cabeça para fazer as tarefas e trabalhos pois gasto menos tempo com brigas" (Aluna K).

Franke (2009:21) faz-nos refletir sobre a lealdade familiar das crianças para com suas famílias. Ao realizar o seu trabalho na sala de aula com as crianças, percebeu que gradualmente conseguia ver nas crianças os representantes de suas famílias com suas leis, suas dinâmicas próprias e particulares, são crianças e alunos comprometidos de forma profunda com suas famílias.

A escola não é melhor que a família e o respeito dos professores pela criança não é nada mais que o respeito pela família de origem. Sendo importante a construção de uma ponte entre família e escola para que os alunos se sintam seguros. Caso contrário a criança poderá sentir que para aprender tem que trair a sua família, e isso trará consequências negativas para a aprendizagem. O professor com essa visão sistêmica terá a possibilidade de trabalhar com os pais, educar a criança e ensinar (Vilaginés, 2007). Em relação à situação com a família, mais um depoimento confirma os efeitos benéficos da constelação: uma aluna disse que agora conseguia reverenciar os pais. "Meu jeito de reverenciar minha mãe é abraçar ela e dizer que a amo, todo dia antes dela sair para trabalhar. Antes eu não falava nada com ela." Outra aluna relata sua mudança de comportamento em casa, saindo de um isolamento que se impôs, na relação com seus pais:

"Estou melhor, mais compreensiva em casa,
destacando a questão de estar em casa. Antes eu queria
era estar ausente em tudo. No almoço eu comia só,
durante minha infância e adolescência. Então eu 
tentava fazer o mesmo com meus pais. Ficar ausente também. Era meu modo de mostrar a eles que eu não era feliz daquela forma. Eu não gosto de comer sozinha" (Aluna K).

Essa mesma aluna disse que aprendeu a não julgar mais os pais como fazia antes. Outro aluno falou da reconciliação dos pais depois que ele constelou o problema familiar. $\mathrm{O}$ aluno $\mathrm{G}$ disse: "a constelação melhorou muito a minha relação com a minha família".

Alunos que participaram como representantes nas constelações de outros colegas, ao serem indagados de como se sentiram durante o momento da constelação, falaram ter se sentido importantes na vida do colega que constelava, e que aprenderam com a situação presenciada: "Me senti parte da vida do outro. Senti como que precisando ajudar o outro a resolver a vida dele" (Aluno D).

Ao se perguntar sobre como a constelação poderia agir na vida dos alunos, as respostas foram: "Ela ajuda a ter uma vida mais próximo da família, a entender $o$ porquê de uns ferirem os outros" (Aluno M). "A constelação familiar melhora a relação com a família, com os colegas. A pessoa se torna uma pessoa cada vez melhor a cada seção de constelação" (Aluno G).

"Ajuda eu entender por que eu sou assim e também ajuda a saber como resolver" (Aluno U). "Na constelação o importante é que as pessoas se expressam através de sentimentos: raiva, tristeza, alegria ou felicidade" (Aluno G) "Durante a sessão de constelação você pode ter vários sentimentos (Aluno E)". Outro resultado observado ocorreu durante a Feira de Ciências de 2017, na dita escola, um grupo de cinco alunos, que já haviam participado da terapia, fizeram um trabalho cujo tema foi Constelação familiar: conhecendo a comunicação com o inconsciente. Durante a apresentação, percebeu-se a dedicação e o interesse em falar sobre o assunto, inclusive com falas de reconhecimento da importância da constelação para a vida familiar e escolar, dizendo que a constelação deveria se tornar uma matéria da escola. Finalizamos, reafirmando com Hellinger (2009) que a consciência nos vincula tão poderosamente à nossa família e a outros grupos que, mesmo inconscientemente, sentimos como exigência e obrigação para nós o que outros membros sofreram ou ficaram devendo no grupo.

\section{Considerações finais}

Os resultados iniciais desta investigação apontaram um grande envolvimento com o projeto por parte dos alunos, mudanças comportamentais em sala de aula, assim como, maior interesse pela aprendizagem, redução de conflitos com colegas e professores; demanda de outros alunos que não realizaram sua constelação familiar solicitando oportunidade para participar do projeto terapêutico, dentre outros.

Acredita-se que uma janela se abre para estudos futuros no tocante à expansão de pesquisas com constelação familiar em contextos escolares, e que se possa estabelecer uma pedagogia sistêmica, ampliando a atuação pedagógica onde se incluam a família e seu entorno social, contribuindo para a aprendizagem e desenvolvimento psicossocial de crianças e jovens.

\section{Referências}

Brasil. Senado Federal. (1988). Constituição da República Federativa do Brasil. Brasília: Senado Federal.

Cansanção, Eliane Calheiros. Tenório, Salvione K. C. M. Conhecendo a Pedagogia Sistêmica. Relatório ISPAB - Conexão Sistêmica, São Paulo - 2012.

Carvalho, José Mauricio. Revista Estudos Filosóficos $n^{\circ} 10 / 2013$ - versão eletrônica - ISSN 2177-2967 http://www.ufsj.edu.br/revistaestudosfilosoficos DFIME - UFSJ - São João del-Rei-MG Pág. 1 - 15. Acesso em 10 de julho de 2017.

Ceará. Secretaria de Educação. Projetos estruturantes. Disponível em: $<$ http://www.ceara.gov.br/governodo-ceara/projetos-estruturantes $>$. Acesso em: 8 de julho de 2011.

Franke-Gricksch M. Você é um de nós. Minas Gerais: Atman;2005.

Hellinger, B. Ordens do Amor. São Paulo: Cultrix, 2007.

Cultrix, 2008

A Simetria Oculta do Amor. São Paulo:

O Amor do Espírito na Hellinger Sciencia.

Patos de Minas: Atman, 2009.

Ikeda, Daisaku, 2017, Educação Soka - Por uma revolução na educação embasada na dignidade da vida, Editora Brasil Seikyo, Makiguchi, Tsunessaburo citado em P.143.

Jares; Xesús R. 2006, Pedagogia da Convivência, 2006, Palas Athena Editora, P.15.

Vilaginés, Mercè La pedagogía sistémica: fundamentos y práctica by Traveset- ISBN 13: 9788478275069 - Editorial Graó - 2007 - Softcover.

Matos, Kelma e Pierre, Claudia, 2014, Cultura de Paz, Ética e Espíritualidade IV, Edições UFC, Coleção Diálogos Intempestivos, P. 25.

Oliveira, C. B. E.; Marinho-Araújo, C. M. A relação família-escola: intersecções e desafios. Estudos de Psicologia, Campinas v. 27, n.1:99-108, janeiro março 2010. Disponível em: http://www.scielo.br/pdf/estpsi/v27n1/v27n1a12.pdf >. Acesso em: 25 jun. 2017.

Ramos, Maria Beatriz J. In: La Rosa, Jorge de. Psicologia e educação: o significado do aprender. Porto Alegre: Edipucrs, 2001.

Santoro, F., Notas de Aula - Apresentação do Metodologia da Pesquisa Científica 2010.2, Programa de Pós Graduação em Informática Unirio.

Seduc, Relatório Preliminar Reorganização Curricular do Ensino Médio. Fortaleza, 2012 